\title{
ERP Adoption and Acceptance in Saudi Arabia Higher Education: A Conceptual Model Development
}

\author{
https://doi.org/10.3991/ijet.v15i15.12039 \\ Mohammed Albarghouthi $\left({ }^{凶}\right)$ \\ Community College of Qatar, Doha, Qatar \\ m.albarghouthi@ccq.edu.qa \\ Baomin Qi \\ Liverpool Hope University, Liverpool, UK \\ T Chengbo Wang \\ Oxford Brooks University, Oxford, UK \\ Muneer Abbad \\ Community College of Qatar, Doha, Qatar
}

\begin{abstract}
Enterprise resource planning (ERP) systems are integrated information systems inter-connecting different functional areas within organisations. It has been widely implemented by large manufacturers globally to enhance operational excellence. However, ERP in the Higher Education sector is less accepted and research in this area still remains at its infancy. Although many higher education institutions (HEIs) have implemented ERP solutions or are in the course of implementing the ERP systems, the failure rate ERP projects within HE is much higher than in other sectors. Through critically examining the existing literature the aim of this research is to develop an extended technology acceptance model (TAM) taking into account the critical factors of ERP adoption for HEIs. Two categories of these factors have been identified from literature based upon a conceptual model is developed. It was clear from reviewing the literature that the main categories of factors that have been studied extensively and shown to be key to understanding ERP adoption and acceptance are: the individual-related factors such as computer self-efficacy and organisational-related factors such as top management.
\end{abstract}

Keywords - Enterprise Resource Planning (ERP), Higher Education (HE), Extended Technology Acceptance Model (TAM).

\section{Introduction}

The Higher Education (HE) sector across the world has in recent years experienced dramatic changes and become a competitive marketplace, for instance the recent UK lifting of 'previously government-controlled' student numbers and the option to 'trade up' on results day (The- rapid-evolution-in-higher-education, 2016). Such changes 
have placed enormous pressure on HE institutions (HEIs) urging them to focus on cutting operational costs hence the improved efficiency. The effective implementation of digital technologies is proven to be optimal solutions for achieving high operational performance.

Enterprise Resource Planning (ERP) systems are integrated information systems enabling an organization to operate seamlessly through sharing the same information across the whole organization. An ERP package contains various modules and components to facilitate and support business functions including finance, sales and marketing, manufacturing and customer services. It can be used to support collaborations and coordination among organizations with the aim to improve the entire supply chain.

ERP systems have been adopted and implemented by almost all large manufacturers across the global and the financial gains are evidenced and well recognized. However, the adoption and implementation of ERP in the HE sector is still in its infancy and research in this area is still limited (Ahmer, 2018). Main reasons of this less widely adoption of ERP in the HE sector include the unique nature of HEIs, standards and quality procedures, and the autonomous and rather isolated operation of individual academic departments (Pollock \& Cornford, 2005). Hence, many challenges exist in implementing ERP within HEIs such as the complexity and difficulty to tailor-made ERP packages to fit individual HEIs operation. Having this said the adoption of ERP systems within the HE sector has been increasing for the last two decade; the implementation of ERP by many large universities in US and Australia have been documented and published in literature.

Anticipating the improved process efficiency and large cost savings it was reported that out of the 800 universities surveyed a large number of them had implemented or in the process of implementing ERP system (EDUCAUSE, 2006). This trend has carried on since this survey, and many universities around the globe have adopted and implementation some types of ERP package. Typical modules designed in an ERP package for HEIs include the automation of admissions, student virtual learning system, and resources management. Received benefits from such implementation have been evidenced from institutions annual report and it is clear that ERP has been viewed as an important strategic initiative for HEIs to manage their business operations (Tortorella and Fries, 2015). However, because of the dynamic nature of HEIs and isolated data and information from highly autonomous functional departments the implementation of ERP system is proven to be more difficult and challenging comparing with those firms within the manufacturing sector (Gates, 2004) (Rabaa'i et al., 2009). The unique nature of HEIs makes the adoption and implementation of ERP more complex and sometimes costly. Research studies conducted on universities indicate that the failure rate of ERP among higher educational institutions is greater than those among other businesses (Abugabah and Sanzogni, 2010; Botta -Genoulaz and Millet, 2006). It is therefore critical for HEIs to understand the challenges involved in the implementation of ERP system to ensure the successful adoption of ERP. The main aims of this research are to examine the existing literature of ERP adoption in the Saudi Arabia higher education sector and 
develop a technology acceptance model (TAM) to guide through the acceptance of ERP technology.

The paper is structured with the following sections. Section 2 reviews relevant literature and reveals the main findings of the review; section 3 discusses and develops an extended TAM model; section 4 draws conclusions and defines future research.

\section{Literature Review}

This section will review the existing literature of ERP adoption in Saudi Arabia higher education. It will also discuss the technology acceptance model (TAM).

\subsection{Research on ERP in the Saudi Arabia higher education sector}

An extensive search of literature has been carried out to locate the studies relating to the adoption of ERP system in HEIs in Saudi Arabia. Academic databases used for the search include Proquest Central, Emerald, ScienceDirect and Sage. Google scholars were also examined to locate publically available researches. The result shows there are only a few studies existing of ERP adoption by Saudi Arabia HEIs. Among these studies a large number of researches have investigated the ERP system, namely the Madar system, adopted by King Saud University (KSU) (Al-Nafjan and Al -Mudimigh, 2011) (AL-Hudhaif, 2012). Though, most of these studies mainly focused on the underline technical aspects of the system implementation. Al- nafjan and Al-Mudimigh (2011) provided a comprehensive literature review indicating the management issues of ERP implementation. Their researches revealed two main factors are important for ERP implementation: the uncertainty and risks perceived by individual users involved in the transition to new ERP systems. The other outcome of their studies indicated that the effectiveness to some extent decreases the resistance to change. Alghathbar (2008) also explored the ERP implementation by King Saud University (KSU), outlining users training, data migration and software package selection are significant to the successful implementation of Madar. Al-Nafjan and Al-Mudimigh (2011) investigated the effective strategies of change management, the tools and processes for managing change to ensure the successful implementation of an ERP system. Conclusions were drawn from their research providing insights and strategies of change management. Conducted by Aldayel et al (2011) the critical successful factors of the Madar implementation were extensively researched examining, identifying fifteen of these factors from the technical prospective and three from the user's perspective. It is indicated that the most important critical success factors of ERP implementation in Higher Education sector in Saudi Arabia was project management. Zubair and Zamani (2014) had the same focus and intended to find out the critical factors influencing the successful implementation of ERP. They carried out a qualitative research revealing the ERP functions, capabilities and institutional performance play important roles. The findings of the study showed that 
the utilization of ERP system is influenced directly and indirectly by work practice, individuals' acceptance, and cultural behavior and believe in system reliability.

Althonayan (2013) proposed a theoretical framework to evaluate stakeholder's performance of ERP systems in HEIs in Saudi Arabia. The main purpose of her study was to develop an integrated model by utilizing and combining Task Technology Fit (TTF), End User Computing Satisfaction (EUCS) and Delone and McLean's IS success frameworks. The results of research study showed that both service quality factors as well as system quality factors have positive influences on stakeholders' performance as well as on their productivity. Al-Hudhaif (2012) conducted his study on King Saud University in order to examine the factors that may influence the ERP implementation from the user's perspective. The main objective of the study is to investigate the situation of Madar implementation. The findings of the research indicated that relationship between ERP implementation challenges as well as satisfaction level is significant. Aljohani et al., (2015) attempted in their case study to examine some important factors (e.g. public negativity, poor integration, dependency on foreign experts, trend pressure) that may affect ERP replacement in one of the universities in Saudi Arabia. The below table 1 summarises the previous research in the ERP adoption within Saudi Arabia higher education.

Table 1. Main findings of literature review

\begin{tabular}{|l|l|}
\hline \multicolumn{2}{|c|}{ Studies on ERP in HEIs In Saudi Arabia, focus and main findings } \\
\hline $\begin{array}{l}\text { Al-Shamlan and Al-Mudimigh (2011); Al- } \\
\text { nafjan and Al-Mudimigh (2011) }\end{array}$ & $\begin{array}{l}\text { Change management strategy and processes } \\
\text { Individual users perceived uncertainty and risks perceived }\end{array}$ \\
\hline $\begin{array}{l}\text { Alghathbar (2008); Zubair and Zamani (2014); } \\
\text { Aldayel et al. (2011); Aljohani et al. (2015) }\end{array}$ & $\begin{array}{l}\text { Critical success factors including: user training, data } \\
\text { migration and software package selection, project } \\
\text { management, individuals acceptance, culture and belief } \\
\text { and work practice }\end{array}$ \\
\hline $\begin{array}{l}\text { Althonayan (2013) } \\
\begin{array}{l}\text { Ullah (2001); Al-Hossan, Al-Mudimigh } \\
\text { (2011); Al-Shamlan and Al- Mudimigh (2011) }\end{array}\end{array}$ & Focused on stakeholder performance evaluation \\
\hline $\begin{array}{l}\text { Alghathbar (2008); Al-Hudhaif (2012); } \\
\text { Agourram (2009) }\end{array}$ & Focused on the post Implementation \\
\hline
\end{tabular}

It can be seen from the above review that most researches in literature have largely focused on the factors that influenced the successful ERP implementation, linking to the implementation and post implementation stage of the ERP life cycle. What happened to the ERP adoption stage and how the decision for such a complex investment was made were not well researched and documented. Although it was mentioned in some literature that the policy makers of some higher education institutions are influenced by the trends of ERP investment as well as the assumed benefits of integrated information systems, the practical high failure rate of ERP project in HE (IT Cortex, 2009) may imply that the adoption decision of ERP project may have been overlooked. This is ascertained in the ERP literature showing the limited exploration of ERP adoption. Therefore, this research will focus on the adoption stage of the ERP life cycle with the aim to develop a theoretical model that will be used when determining the ERP adoption higher education. As ERP systems 
are type of information technology, next section will examine the technology acceptance model (TAM).

\subsection{TAM adoption of ERP system in the context of HE}

Different research studies have been dedicated to understand user acceptance of information technology. Many well- established frameworks, theories and theoretical models have been utilised to examine user acceptance of a technology. Over the past two decades, some theoretical models have governed the theoretic basis of information technology acceptance (Kim \& Malhotra, 2005) (Adam, et.al. 1992) among which the technology acceptance model (TAM) (Davis, 1986) is the most widely adopted to discuss the acceptance and use a technology, as shown in Figure 1.

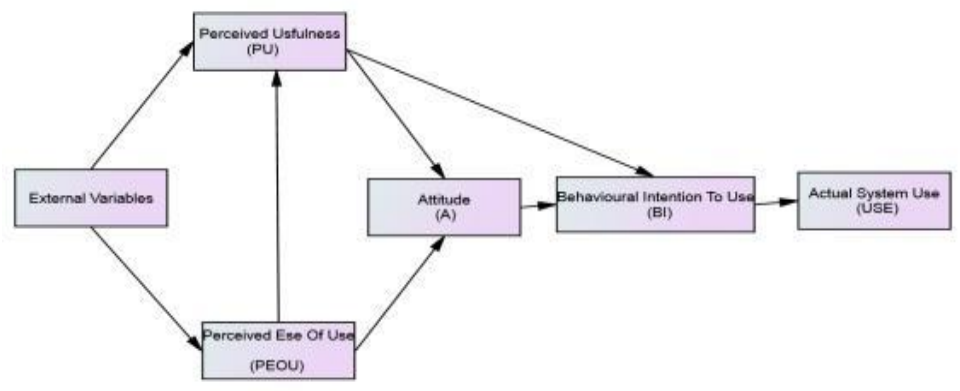

Fig. 1. Technology Acceptance Model (Davis, 1986)

Different researchers attempted to extend the TAM model with new variables and examine their influence on PEOU and PU in order to recognize boundary conditions. For instance, Agarwal and Prasad (1999) used five individual factors (e.g. training, prior experiences, job position, level of education, and role with regard to technology) as external factors that will influence PEOU and PU. Igbaria et al, (1995) used three organizational factors (e.g. training, top management support and computer support) as external factors of PEOU and PU. Sternad et al. (2011) grouped the antecedents of PEOU and PU into individual, organizational and technological variables. The adoption of TAM has been criticized by its lack of detailed guidance with only providing a general framework. Researches such as Chuttur's (2009) therefore reconstructed an extended model to address various determinant variables of the PU and PEOU. PU and PEOU in the TAM framework may not entirely depict the users' intention to adopt information systems (IS), and as a result researchers should study how other factors influence user acceptance as well as the usefulness and the ease of use of IS (Mathieson, 1991).

TAM in an ERP environment in general was examined in some researches (Amoako- Gyampah and Salam, 2004) (Al-Jabri and Roztocki, 2015) to explore the external factors of ERP projects for instance discussing the perceived information transparence factor. It is worth noting that the majority of the research studies in this area were conducted on the manufacturing ERP project; there is a lack of research 
studies focusing on the acceptance of ERP in higher education. In this local, this research will explore the external factors that may affect the adoption of ERP systems in HEIs. An extended version of TAM will be developed in next section of the adoption of ERP systems in Saudi Arabia HEIs and indeed a wider context.

\section{$3 \quad$ Research Model Development}

The business operations and organisational structure of HEIs differ from companies and firms. The autonomous nature and individual user requirements of various departments within a HE setting indicate that the organizational and individual factors may play significant roles demanding special attention. Ascertained by Venkatesh (2000) Helo et al. (2008) that unlike other information systems, the main issues of ERP within HE is not technological such as the complexity, compatibility and standardization but rather organizational and individual related. Emphasised by these studies and the existing literature in the area of information technology (IT) adoptions, variables in relation to these two perspectives are particularly selected and further examined; based upon the analysis of literature a new research model i.e. extended TAM is developed in this section.

\subsection{Organisational variables}

User training: A large amount of previous studies (Bradley and Lee, 2007; Koh's et al., 2009; Noudoostbeni et al., 2009; Kale, 2000) on IT and ERP systems adoption in other sectors point out that user training is an indispensable factor for the successful implementation of ERP packages. User training and education are regarded as the most important factors, determining and influencing the success of ERP implementation. This is because user training and education not only facilitate the adaption of new ERP system but also the facilitation of the process of change in an organization (Zornada, 2005). Effective training is an invaluable factor that fosters a positive attitude regarding the system among users (Choi et al., 2007). Inadequate training for ERP users decreases ease of use of the technology therefore increases user resistance, which may have major consequences on ERP system success and usage (Bradley, 2008). The study conducted by Amoako- Gyampah and Salam (2004) also suggested that user training and education affects both the perceived usefulness and ease of use of ERP systems indicating the significance of incorporating the user training variable when exploring the acceptance of new technologies.

Top management support: The importance of support from the top management team in the successful IT adoption and acceptance has been understood by a number of researchers (Zhang et al., 2011; Woo 2007), this is especial true when the results are dynamic and uncertain. According to Liang et al. (2007), top management plays the coercive leadership role to help the employees eliminate any doubts about the technological use. Sternad and Bobek (2013) defined ERP support as "the degree to which an individual views adequate ERP support as the reason for his or her successful ERP usage". Previous studies have confirmed that support from top 
management have a positive effect on the attitude's performance of users especially during the adoption of new ERP technologies. Support from top management improves the users' attitudes toward micro and reduce computer anxiety (Igbaria and Chakrabarti, 1990).

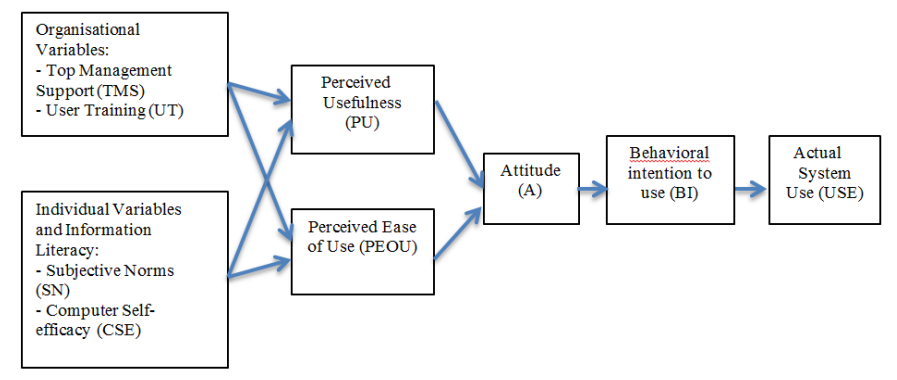

Fig. 2. An extended technology acceptance model for ERP adoption in HE

Lee et al. (2010) examined the influence of top management support on behavior intention of ERP systems. The finding of their study indicated that top management support is critical factor for perceive ease of use and perceive usefulness. Top management support strongly and positively affect perceive ease of use and usefulness of ERP systems (Shih and Huang, 2009).

\subsection{Individual variables and information literacy}

Computer Self-Efficacy (CSE): Self-efficacy implies the belief in one's capacity to perform a given task, or an individuals' belief in his own capacity to successfully undertake an activity (Bandura, 1997). Various studies have established that perceptions of self-efficacy may influence decisions on what behaviors to enact, persistence towards certain behavior, as well as an individual's actual performance accomplishments with regard to behaviour. In the context of adopting information technologies and systems the term of computer self-efficacy is recognized and defined as a judgment of one's capability to use a computer. According to Davis et al. (1989) Venkatesh and Davis (1996) when adopting new technologies computer self- efficacy is an important factor for the success of adoption and implementation. Revealed by these researches it is an antecedent of the perceived ease of use (PEOU) and determines ones' capability to use particular technological tools.

It is also an important antecedent of the perceived usefulness of the technologies adopted. To conclude, computer self- efficacy has an influence on both user perceive ease of use and subsequently on perceive usefulness of ERP.

Subject Norms (SN): According to Venkatesh's (1998) view social influence is a function of two factors, including subjective norms and social factors. Subjective norms may be described as a person's perception that most people who are important to him/her think that he/she should or should not perform the behavior in question. Early TAM researchers abandoned subjective norms as a study subject on the 
realization that there were no significant results as far as subjective norm have a considerable influence on perceived usefulness when adopting new information technologies. There are other studies having also confirmed subjective norm to determine perceived usefulness to the greatest extent, particularly when the user hold limited experience with the technology in question. Additionally, Hartwick and Barki (1994) and Melone (1990) argued that subjective norm could have a positive and considerable effect on the intention to use technologies in mandatory situations.

Development of new research model: Existing literature of IT and ERP adoption and acceptance using TAM in other sectors has been examined in the above sections which revealing the considerations and particular attention placed on two main categories of factors: organisational and individual related. Although higher education institutions are unique entities with unique organisation, they do share commonalities with business in general. To ensure the successful adoption of new technologies and indeed ERP packages by HEIs the above revealed factors have therefore been incorporated in the TAM model.

Figure 2 shows a new model that is developed for the ERP acceptance and adoption within the context of Saudi Arabia higher education, and should also be applicable for the HE sectors in general.

\section{Conclusion}

The literature review undertaken in this research reveals some of the gaps in the field of studies on ERP adoption in Saudi Arabia HEIs as well as the general HE sectors across the world. This is particular true that very limited research focusing on the ERP adoption stage providing clear instructions for the effective adoption and implementation of ERP systems within HEIs and there is a lack of research that has investigated the adoption of ERP systems in the HEI environment. It was clear from reviewing the literature that there were two main categories of variables that had been studied and shown to be relevant to understanding technology acceptance: individual factors and information literacy (e.g., computer self -efficacy and subjective norm) and organisational factors (top management support and user training). Research indicates that both categories have an influence upon technology acceptance. Based on the literature review on ERP systems, as well as on the TAM model, the identified factors have been incorporated in a single model to develop a conceptual framework for ERP adoption in HEIs. Through reviewing the current literature this research has developed a new extended technology acceptance model to address the ERP adoption and acceptance decisions.

There are two main limitations of this research. This research is firstly constrained by the limited literature sources available in the specific research area; and secondly only the two most important variables being incorporated in the developed conceptual research model. The future research will be focused on the empirical study to verify the developed research model. Quantitative research may be adopted to explore the relationships between the variables of the model. Research data is intended to be collected from six universities within Saudi Arabia. 


\section{$5 \quad$ References}

[1] Abbas, M. (2011) ERP Systems in HEI Context from a Multiple Perspective View: A Case Study. Doctoral dissertation. Manchester: University of Manchester.

[2] Abugabah, A. and Sanzogni, L. (2010) Enterprise Resource Planning (ERP) System in Higher Education: A Literature Review and Implications. International Journal of Human and Social Sciences, 5(6), pp. 395-399

[3] Adams, D.A., Nelson, R.R. and Todd, P.A. (1992) Perceived Usefulness, Ease of Use, and Usage of Information. MIS Quarterly, 16(2), pp. 227-247. https://doi.org/10.2307/249577

[4] Agarwal, R. and Prasad, J. (1999) Are Individual Differences Germane to the Acceptance of New Information Technologies? Decision Sciences, 30(2), pp. 361-91. https://doi.org/ 10.1111/j.1540-5915.1999.tb01614.x

[5] Ahmer, Z. (2018) Usage of enterprise resource planning systems in higher education institutions in Pakistan, available online: https://uhra.herts.ac.uk/bitstream

[6] ALdayel, A.I., ALdayel, M.S. and Al-Mudimigh, A.S. (2011) The Critical Success Factors of ERP Implementation in Higher Education in Saudi Arabia: A Case Study. Journal of Information Technology \& Economic Development, 2(2)

[7] Alghathbar, K. (2008) Practical ERP Implementation in Government Organization. In CSREA EEE (pp. 343-349)

[8] Al-Hudhaif, S. (2012) ERP implementation at King Saud University, Global Journal of Management and Business Research, 12(5).

[9] Al-Jabri, I. and Roztocki, N. (2015) Adoption of ERP Systems: Does Information Transparency Matter? Telematics and Informatics, 32(2015), pp. 300-310. https://doi.org/ 10.1016/j.tele.2014.09.005

[10] Aljohani, A.M., Peng, A. and Nunes, M. (2015) Critical Factors Leading to ERP Replacement in Higher Education Institutions in Saudi Arabia: Preliminary Results. iConference 2015 Proceedings

[11] Al-Mashari, M. (2003) A Process Change-Oriented Model for ERP Application. International Journal of Human-Computer Interaction, 16(1), pp. 39-55. https://doi.org/10. 1207/s15327590ijhc1601_4

[12] Al-Mudimigh, A.S., Ullah, Z. and Saleem, F. (2009) A Framework of an Automated Data Mining Systems Using ERP Model. International Journal of Computer and Electrical Engineering, 1(5), p. 651. https://doi.org/10.7763/ijcee.2009.v1.101

[13] Al-Nafjan, A.N. and Al-Mudimigh, A.S. (2011) The Impact of Change Management in ERP System: A Case Study of Madar. Journal of Theoretical \& Applied Information Technology, 23(2), pp.209-214

[14] Althonayan, M. (2013) Evaluating Stakeholders Performance of ERP Systems in Saudi Arabia Higher Education. Doctoral dissertation. Brunel University, School of Information Systems, Computing and Mathematics

[15] Amoako-Gyampah, K. and Salam, A.F. (2004) An Extension of the Technology Acceptance Model in an ERP Implementation Environment. Information \& Management, 41(6), pp. 731-745. https://doi.org/10.1016/j.im.2003.08.010

[16] Bandura, A. (1986) The Explanatory and Predictive Scope of Self-efficacy Theory. Journal of Social and Clinical Psychology, 4(3), pp. 359-373. https://doi.org/10.1521/jscp.1986.4. $\underline{3.359}$

[17] Botta-Genoulaz, V. and Millet, P.A. (2006) An Investigation into the Use of ERP Systems in the Service Sector. International Journal of Production Economics, 99(1-2), pp. 202221. https://doi.org/10.1016/j.ijpe.2004.12.015 
[18] Bradley, J., Lee, C. (2007) ERP Training and User Satisfaction: A Case Study. Journal of Enterprise Information Systems, 3(4), pp. 33-50. https://doi.org/10.4018/jeis.2007100103

[19] Choi, D.H., Kim, J. and Kim, S.H. (2007) ERP Training with a Web-based Electronic Learning System: The Flow Theory Perspective. International Journal of HumanComputer Studies, 65(3), pp. 223-243. https://doi.org/10.1016/j.ijhcs.2006.10.002

[20] Chuttur, M.Y. (2009) Overview of the technology acceptance model: Origins, developments and future directions. Working Papers on Information Systems, 9(37), pp.937.

[21] Davis, F D. (1986) A Technology Acceptance Model for Empirically Testing New Enduser Information Systems: Theory and Results. Doctoral dissertation. Sloan School of Management, Massachusetts Institute of Technology

[22] Davis, F.D. and Venkatesh, V. (1996) A critical assessment of potential measurement biases in the technology acceptance model: three experiments. International Journal of Human-Computer Studies, 45(1), pp.19-45. https://doi.org/10.1006/ijhc.1996.0040

[23] EDUCAUSE (2006) Core Data Service Fiscal Year 2005 Summary Report, EDUCAUSE

[24] Gates, K.F. (2004) Evaluating the North-American Pilot for SAP's Campus Management System, in Hellens, L., Nielsen, S. and Beekhuyzen, J. (Eds.), Qualitative Case Studies on Implementation of Enterprise Wide Systems. 192-210. Hershey, USA: Idea Group Publishing. https://doi.org/10.4018/978-1-59140-447-7.ch012

[25] Helo, P., Anussornnitisarn, P. and Phusavat, K. (2008) Expectation and Reality in ERP Implementation: Consultant and Solution Provider Perspective. Industrial Management \& Data Systems, 108(8), pp. 1045-1059. https://doi.org/10.1108/02635570810904604

[26] Igbaria, M. and Chakrabarti, A. (1990) Computer anxiety and attitudes towards microcomputer use. Behaviour \& Information Technology, 9(3), pp.229-241. https://doi. org/10.1080/01449299008924239

[27] Kale, V. (2000) Implementing SAP r/3. Indianopolis, SAMS.

[28] Kim, S.S. and Malhotra, N.K. (2005) A longitudinal model of continued IS use: An integrative view of four mechanisms underlying postadoption phenomena. Management science, 51(5), pp.741-755. https://doi.org/10.1287/mnsc.1040.0326

[29] Koh, S.C.L., Gunasekaran, A. and Cooper, J.R. (2009) The Demand for Training and Consultancy Investment in SME-specific ERP Systems Implementation and Operation. International Journal of Production Economics, 122(1), pp. 241-254. https://doi.org/10.101 6/j.ijpe.2009.05.017

[30] Lee, D., Lee, S.M., Olson, D.L. and Hwan Chung, S. (2010) The Effect of Organizational Support on ERP Implementation. Industrial Management \& Data Systems, 110(2), pp. 269-283. https://doi.org/10.1108/02635571011020340

[31] Liang, H., Saraf, N., Hu, Q. and Xue, Y. (2007) Assimilation of Enterprise Systems: The Effect of Institutional Pressures and the Mediating Role of Top Management. MIS Quarterly, pp. 59-87. https://doi.org/10.2307/25148781

[32] Lu, Y., Zhou, T. and Wang, B. (2009) Exploring Chinese Users' Acceptance of Instant Messaging Using the Theory of Planned Behavior, the Technology Acceptance Model, and the Flow Theory. Computers in Human Behavior, 25(1), pp. 29-39. https://doi.org/10.101 6/j.chb.2008.06.002

[33] Mathieson, K. (1991) Predicting User Intentions: Comparing the Technology Acceptance Model with Theory of Planned Behavior. Information Systems Research, 2(3), p. 173. https://doi.org/10.1287/isre.2.3.173

[34] Noudoostbeni, A., Yasin, N.M. and Jenatabadi, H.S. (2009) April. To Investigate the Success and Failure Factors of ERP Implementation within Malaysian Small and Medium 
Enterprises. International Conference on Information Management and Engineering, 2009. ICIME'09. pp. 157-160. IEEE. https://doi.org/10.1109/icime.2009.66

[35] Pollock, N. \& Cornford, J. (2005) Implications of enterprise resource planning systems for universities. An Analysis of Benefits and Risks. The Observatory on Borderless Higher Education, London

[36] Rabaa'i, A.A., Bandara, W. and Gable, G. (2009) December. ERP systems in the higher education sector: a descriptive study. In Proceedings of the 20th Australasian Conference on Information Systems (pp. 456-470).

[37] Shih, Y.Y., Huang, S.S. (2009) The Actual Usage of ERP Systems: An Extended Technology Acceptance Perspective. Journal of Research and Practice in Information Technology, 41(3), pp. 263-276

[38] Sternad, S., Gradisar, M. and Bobek, S. (2011) The Influence of External Factors on Routine ERP Usage. Industrial Management \& Data Systems, 111(9), pp. 1511-1530. https ://doi.org/10.1108/02635571111182818

The-rapid-evolution-in-higher-education (2016) The rapid evolution in higher education, available online https://www.telegraph.co.uk/education/secondaryeducation/10844094/ The-rapid-evolution-in-higher-education.html, accessed 12/05/2019

[39] Tortorella, G. L., \& Fries, C. E. (2015). Reasons for adopting an ERP system in a public university in Southern Brazil. In Proceedings of International conference on operations excellence and service engineering, Orlando, USA (pp. 1-15).

[40] Venkatesh, V. (2000) Determinants of Perceived Ease of Use: Integrating Control, Intrinsic Motivation, and Emotion into the Technology Acceptance Model. Information Systems Research, 11(4), pp. 342-365. https://doi.org/10.1287/isre.11.4.342.11872

[41] Venkatesh, V. and Davis, F. (2000) A Theoretical Extension of the Technology Acceptance Model: Four Longitudinal Field Studies. Management Science, 46(2), pp. 186204. https://doi.org/10.1287/mnsc.46.2.186.11926

[42] Woo, H.S. (2007) Critical Success Factors for Implementing ERP: The Case of a Chinese Electronic Manufacturer. Journal of Manufacturing Technology, 18(4), pp. 431-442. https ://doi.org/10.1108/17410380710743798

[43] Zornada, L. and Velkavrh, T.B. (2005) Implementing ERP systems in higher education institutions. In Information Technology Interfaces, 27th International Conference on (pp. 307-313). https://doi.org/10.1109/iti.2005.1491143

[44] Zubair, S. and Zamani, A.T. (2014) Critical factors affecting Oracle E-Business Suite enterprise resource planning (ERP) R12 implementation: A case study of Saudi Arabia's university. information systems, 7(3). https://doi.org/10.5120/ijais14-451158

\section{Authors}

Mohammed Albarghouthi works for Community College of Qatar in Qatar. Can be contacted through Email m.albarghouthi@ccq.edu.qa.

Baomin Qi works for Business School in Liverpool Hope University at Hope Park in, Liverpool, UK.

T Chengbo Wang is with Business School in Oxford Brooks University at Oxford, UK.

Muneer Abbad is with Business School, Community College of Qatar, Doha, Qatar.

Article submitted 2019-10-26. Resubmitted 2020-05-02. Final acceptance 2020-05-04. Final version published as submitted by the authors. 